\title{
Biodegradable film production from agroforestry and fishery residues with active compounds
}

\author{
Marisa C. Gaspar ${ }^{\mathrm{a}, *}$, João Leocádio ${ }^{\mathrm{a}}$, Cátia V.T. Mendes ${ }^{\mathrm{a}}$, Martim Cardeira ${ }^{\mathrm{b}}$, \\ Naiara Fernández $^{\mathrm{b}}$, Ana Matias ${ }^{\mathrm{b}}$, Maria G.V.S. Carvalho ${ }^{\mathrm{a}}$, Mara E.M. Braga ${ }^{\mathrm{a}, *}$ \\ ${ }^{a}$ University of Coimbra, CIEPQPF, Department of Chemical Engineering, Rua Sílvio Lima, Pólo II - Pinhal de Marrocos, 3030-790, Coimbra, Portugal \\ ${ }^{\mathrm{b}}$ iBET, Instituto de Biologia Experimental e Tecnológica, Food \& Health Division, 2781-901, Oeiras, Portugal
}

\section{A R T I C L E I N F O}

\section{Keywords:}

Residues

Biorefinery

Packaging system

Chitosan-derivative

Pine stumps

Antioxidant extract

\begin{abstract}
A B S T R A C T
An increasing interest in food packaging materials without environmental impact and able to improve shelf life has emerged in the last decade. The aim of this work was to produce biodegradable films from agroforestry (pine stumps) and fishery (chitosan) residues with active compounds. N-carboxybutylchitosan (CBC) films were developed with the inclusion of a reinforcing material (cellulose), plasticizers (silicone or glycerol) and/or an antioxidant extract from pine stumps. These films were characterised in terms of physicochemical properties and cytotoxicity. Films with glycerol presented higher elasticity, while pure CBC films showed the most adequate water vapour barrier properties. Films had thickness values $(55-70 \mu \mathrm{m})$ similar to commercial ones, and slightly hydrophobic properties (contact angles of $\sim 84-102^{\circ}$ ). All films revealed low cytotoxicity, with the exception of the extract-loaded films. However, these have potential to increase food shelf life and decrease photo-oxidation, due to their opacity/brown colour.
\end{abstract}

\section{Introduction}

Food packaging systems have the main function of maintaining the quality and safety of food, being also essential to identify and give information about the product (Cruz et al., 2018). A wide range of materials may be used for packaging applications, and many advances in this area have been made. The first materials used for packaging applications were paper, metal and glass, but plastics (polymer materials) are currently the most common materials for food packaging. Petroleum-based polymers including polyethylene terephthalate (PET), polyvinylchloride (PVC), polyethylene (PE), polypropylene (PP), polystyrene (PS), and polyamide (PA) have been widely used in the food packaging area because they are easily available at relatively low cost, and present good mechanical and gases permeability properties (Siracusa et al., 2008). However, most of these materials are synthetic and non-biodegradable neither eco-friendly, generating a lot of wastes (14.5 million tons of packaging plastic in 2017, from European Union member states and some non-member countries) and causing environmental and health issues (Eurostat, 2020). Considering the clear need for more sustainable materials, biobased plastics (biopolymers) have gained interest for use as environmentally friendly food packaging applications (Cruz et al., 2018; Siracusa et al., 2008).

Biodegradable and renewable materials should be preferred alternatives in the food packaging applications to reduce the tons of plastic waste that are produced every year, and to decrease the use of materials derived from fossil fuels (Meritaine da et al., 2018). These materials may be based on polysaccharides, proteins and lipids extracted from some residues, such as those from agroforestry and fishing industries. Furthermore, natural film-forming materials may be used to produce thin layers of biopolymers that can be placed on or between food

Abbreviations: C, films of N-carboxybutylchitosan (CBC); CC, films of CBC plus cellulose; CS, films of CBC plus silicone; CCS, films of CBC plus cellulose plus

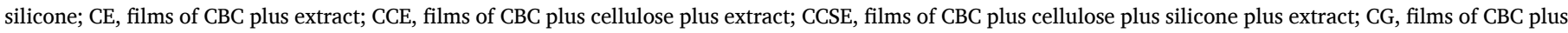

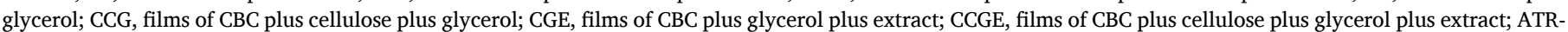

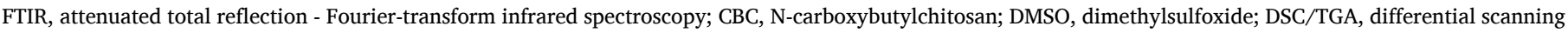

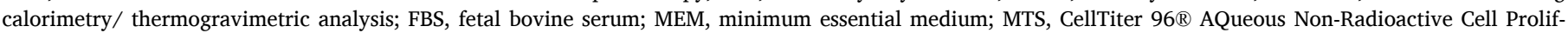

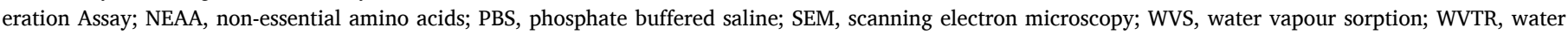
vapour transmission rate.

* Corresponding author.

E-mail addresses: marisagaspar@eq.uc.pt (M.C. Gaspar), marabraga@eq.uc.pt (M.E.M. Braga). 
structures, constituting edible films or coatings (Falguera et al., 2011). Common polysaccharides from vegetal sources such as cellulose, pectin, and starch, and agar, alginate, carrageenan, and chitin from marine sources have been widely studied along with some proteins (gelatine, soy and zein), lipids and waxes, as protective barriers (Farahnaky et al., 2013; Meritaine da et al., 2018). Cellulose is particularly attractive for these applications, since it is the most abundant polymer in nature and it is present in all fruits, vegetables and in different structures of higher plants (e.g. leaves, trunks and stumps) (Meritaine da et al., 2018). Moreover, it is biodegradable and obtained at low cost, consisting in a promising alternative to common plastics. However, in plant tissues, cellulose forms a complex structure with lignin and hemicelluloses, and therefore biological and chemicals treatments need to be applied to separate this water-insoluble and linear polysaccharide (Mendes et al., 2020; Meritaine da et al., 2018).

Chitin, the second most abundant natural polymer, is also a linear polysaccharide, being present in the shells of insects and crustaceans and fungal cell walls (Meritaine da et al., 2018). The main source of this natural polymer are crab and shrimp shells from seafood industry residues (Muxika et al., 2018). From chitin it is possible to obtain other interesting polymers by deacetylation, such as chitosan, which is a low toxic and biodegradable polymer and presents antibacterial and antifungal properties (Cruz et al., 2018; Muxika et al., 2018). As a result, chitosan and its derivatives have been extensively studied and proposed for numerous applications in distinct areas (Dias et al. 2011; Pires et al., 2018; Souza et al., 2013), including the development of film-based systems (e.g. edible films) in the food preservation and food technology (Mujtaba et al., 2019; Ren et al., 2017; Serrano-León et al., 2018; Souza et al., 2017; Vlacha et al., 2016). Mainly due to its antimicrobial activity, chitosan is an interesting component to develop active packaging, i.e. a type of packaging that is able to extend shelf life or to improve safety or sensory properties, maintaining the food quality (Siracusa, 2016). In the specific case of the $N$-carboxybutylchitosan (CBC), a chitosan derivative, it exhibits enhanced film-forming properties, and bioadhesive and bacteriostatic effects, being soluble in water and under acidic, neutral or basic conditions, contrary to chitosan, which is only soluble in acidic medium (dos Santos et al., 2005; Muzzarelli et al., 1989).

However, due to the poor characteristics of some of these natural materials regarding its stability or barrier properties, chemical modifications, or the use of additives (e.g., reinforcing materials, plasticizers, etc.) may have to be applied when producing films (Farahnaky et al., 2013; Meritaine da et al., 2018; Tian et al., 2010; Vlacha et al., 2016). Synthetic plasticizers include some types of silicones, which may be applied as coatings in natural cork stoppers used for alcoholic beverage bottles (Ortega-Fernandez et al., 2006). Silicone coatings also prevent sticking of food or food packaging to different surfaces, being in general water and oil repellent (Geueke, 2015). However, these polymers are very persistent to biological degradation, and should be used with caution.

On the contrary, glycerol is a non-toxic and biodegradable plasticizer, being widely used in food packaging applications. Moreover, it has a preservative function in some foods and beverages (Pagliaro and Rossi, 2008).

The incorporation of other antimicrobial and/or antioxidant compounds may increase the performance of packaging systems by controlling food spoilage from undesirable microorganism and by improving oxidative stability (Leimann et al., 2018, Muxika et al., 2018). Synthetic antioxidants such as butylated hydroxyanisole (BHA) or butylated hydroxytoluene (BHT) have been used for this purpose. However, this type of compounds present toxicological concerns, strict regulation, and rejection by consumers who prefer natural additives. Therefore, to reduce the application of these substances in food packaging, some researchers have already investigated and included plant-based extracts with antioxidant activity, namely extracts from ginger, rosemary, and tea tree, among many others (Hassanzadeh et al., 2017; Lekjing 2016; Mujtaba et al., 2019; Muxika et al., 2018;
Serrano-León et al., 2018; Souza et al., 2017).

Based on the recent strategies from food industry, the aim of this work was to use residues from agroforestry and fishing industries, in a biorefinery context, for developing biodegradable films for food packaging. The chitosan-derivative $\mathrm{CBC}$ was used and to improve their mechanical properties, the addition of a reinforcing material (cellulose) was evaluated, and a plasticizer (silicone or glycerol) was tested to increase their flexibility. Finally, the addition of an antioxidant pine extract was also tested to make the packaging system active. Films were characterised in terms of chemical composition, thickness, colour, morphology, wettability, mechanical properties, water vapour sorption and transmission rate, and cytotoxicity.

\section{Materials}

\subsection{Chemicals and solvents}

Chitosan (medium molecular weight, 75-85 \% deacetylated), levulinic acid (98\%), sodium borohydride (ReagentPlus ${ }^{\circledR} 99 \%$ ), glycerol (1,2,3-propanetriol, $99.5 \%$ ), dialysis membranes (MWCO 12,000 Da), Minimum essential medium (MEM), with Earle's Balanced Salts and $2.0 \mathrm{mM}$ L-glutamine, phosphate buffered saline (PBS) $\mathrm{pH}=7.4$, were obtained from Sigma-Aldrich (USA). Dimethylsulfoxide (DMSO) $99.7 \%$ was obtained from Fisher Scientific (USA). Silpuran ${ }^{\circledR} 2130$ A/B (RTV-2 silicone adhesive/biocompatible) was purchased from Wacker Chemie AG (Germany). Ethanol absolute ( $\geq 99.5 \%$ ), and glacial acetic acid ( $\geq 99.8 \%$ ) were obtained from Merck (Darmstadt, Germany). Non-essential amino acids (NEAA) and fetal bovine serum (FBS) of South America origin were obtained from Life Technologies (UK) and Biowest (USA), respectively. Mouse fibroblasts NCTC clone 929 were purchased from ATCC - American Type Culture Collection; CellTiter 96® AQueous Non-Radioactive Cell Proliferation Assay (MTS) reagent assay was obtained from Promega (USA). $\mathrm{NaOH}$ p.a. (pro analysis) was purchased from EKA Chemicals (USA), and anthraquinone ( $49.55 \% \mathrm{w} / \mathrm{v}$ ) and $\mathrm{ClO}_{2}$ $(6 \mathrm{~g} / \mathrm{L})$ from a local supplier (Portugal). $\mathrm{H}_{2} \mathrm{O}_{2}(30 \% \mathrm{w} / \mathrm{v})$ was from Panreac (Barcelona), $\mathrm{H}_{2} \mathrm{SO}_{4}$ (72 \%) from Chem-Lab (Belgium), $\mathrm{CaCO}_{3}$ (99\%) from Alfa Aesar (USA) and glucose ( $>99 \%$ ) was obtained from Riedel-de Haën (USA). Milli-Q water was employed in the films preparation, water angle contact, water vapour experiments, and cytotoxicity assays.

\subsection{Raw materials}

Some raw materials and compounds (cellulose and pine extract) were obtained in the context of previous works, and used in these films, according to the biorefinery concept.

Pure cellulose (99.1\%) was obtained from a sequential pretreatment applied on Pinus pinaster residues (stumps chips), provided by the Biomass Thermoelectrical Centre of Terras de Santa Maria, Oliveira de Azeméis, Portugal), consisting on: i) steam explosion, ii) organosolv (30\% ethanol at $170{ }^{\circ} \mathrm{C}$ for $30 \mathrm{~min}$ ), iii) soda cooking $\left(50 \mathrm{~g} \mathrm{~L}^{-1}\right.$ $\mathrm{NaOH}, 0.2 \%$ anthraquinone, at $3 \%$ consistency and $162{ }^{\circ} \mathrm{C}$ for 180 min), iv) oxygen delignification and v) Elemental Chlorine Free (ECF) bleaching sequence, as described elsewhere (Mendes et al., 2020).

Antioxidant aqueous extracts of stump residues were used due to their antioxidant activity. Stump extracts showed high total phenolic content close to $440 \mathrm{mg}$ gallic acid equivalents/g extract, and high antioxidant activity, represented by the low $\mathrm{IC}_{50}$, about $6 \mu \mathrm{g} / \mathrm{mL}$, as detailed in a previous work (Gaspar et al., 2019).

\section{Development of food packaging films}

\subsection{Preparation of carboxybutylchitosan ( $C B C)$}

$\mathrm{N}$-carboxybutylchitosan (CBC) was prepared from the reaction of chitosan (dissolved in levulinic acid solution), with a reducing agent 
(the sodium borohydride), as previously described (Rinaudo et al., 2001). Briefly, and according to the conditions needed to obtain the referred chitosan-derivative, the chitosan was dissolved overnight $(12 \mathrm{~h}$, $25^{\circ} \mathrm{C}$ ), and then heated for $2 \mathrm{~h}$ at $80^{\circ} \mathrm{C}$. The solution was then cooled up to room temperature, and the reducing agent added and homogenized for $30 \mathrm{~min}$ at $25^{\circ} \mathrm{C}$, followed by heating $\left(80^{\circ} \mathrm{C}\right)$ for $1 \mathrm{~h}$, under constant stirring. The obtained product was dialysed for 4 days to remove impurities and unreacted products, and by using wet dialysis membranes, and replacing the dialysis distilled water 2-3 times/day. The solution was then concentrated ( $1 \mathrm{~g}$ chitosan/ $70 \mathrm{~mL}$ ) using a rotary evaporator (Rotavapor ${ }^{\circledR}$ R-210, Buchi, Switzerland), and degasification was carried out in an ultrasound bath (Elmasonic, S 30H, Germany).

\subsection{Film casting step}

Cellulose, silicone (Silpuran ${ }^{\circledR} 2130$ A/B), glycerol and/or stump extract were added to $\mathrm{CBC}$ solution $(10 \mathrm{~mL}$ of casting solution was used for all samples), according to Table 1 . The formulations were prepared in triplicate and the indicated percentage compositions were chosen according to preliminary assays, and to some literature data (Bombaldi de Souza et al., 2016; Mujtaba et al., 2017; Ren et al., 2017; Vlacha et al., 2016). The mixture was homogenised for $30 \mathrm{~min}$ under magnetic stirring $(700 \mathrm{rpm})$. For formulations containing the stump extract, a further homogenisation step with an Ultra-turrax ${ }^{\circledR}$ (IKA, T18 basic, Germany) was needed (1 min, 11,000 rpm). The pure CBC solution (control) or supplemented with other compounds was poured into Petri dishes, and placed in an oven at $50{ }^{\circ} \mathrm{C}$ for $24 \mathrm{~h}$.

\section{Films characterisation}

CBC films were characterised in terms of physicochemical properties, namely thickness, colour, water angle contact, mechanical properties, chemical composition, water vapour barrier characteristics, and morphology. In vitro cytotoxicity assays were also carried out to infer about the possibility to have edible films.

\subsection{Thickness}

A digital micrometer (Tesa Micromaster Electronic Micrometers
IP54) with a precision of $0.001 \mathrm{~mm}$ was used to measure the thickness of the prepared films, values that are important for the calculation of their mechanical properties. At least five measurements were made for each film, in different positions.

\subsection{Water contact angle}

The static contact angle of films with Milli-Q water (10 $\mu \mathrm{L}$ drop) was evaluated by using the instrument Dataphysics Instruments $\mathrm{GmbH}$, OCA20 (Germany) and the sessile drop method (Pires et al., 2018). At least five measurements were made for each sample (a film square of approximately $1 \mathrm{~cm}^{2}$ ).

\subsection{Colour}

The colorimeter Minolta CR-200b (Osaka, Japan) was used to measure the films colour (at least five measurements per film, $8 \mathrm{~mm}$ diameter measuring area) employing the CIELAB scale. The calibration was performed with the white colour plate. Each film was then placed on this plate to measure its colour. Films were evaluated regarding lightness, $\mathrm{L}^{*}$ $(0=$ black to $100=$ white $)$, and chromaticity coordinates $a^{*}(-60=$ green to $+60=$ red $)$ and $b^{*}(-60=$ blue to $+60=$ yellow $)$. These values were given by the equipment and based on these parameters, the Hue angle, chroma $\left(C^{*}\right)$, colour difference related to CBC control films $(\Delta \mathrm{E})$, and differences in tonality (hue difference, $\Delta \mathrm{H}$ ) in relation to the controls were calculated, as previously described (Pires et al., 2018).

\subsection{Mechanical properties}

Mechanical properties of films were measured (2-4 samples per film) by resorting to a texturometer (Stable micro systems TA XT Express, UK). Films were carefully cut into dumb-bell-shape, with $50 \mathrm{~mm}$ length, $10 \mathrm{~mm}$ width at ends, and $5 \mathrm{~mm}$ width of narrow portion, according to ISO 527-2 (ISO, 1996), and the speed of tension test was $0.1 \mathrm{~mm} / \mathrm{s}$. Maximum tensile strength (Max $\sigma, \mathrm{MPa}$ ) and the tensile strain at break $(\varepsilon, \%)$ were calculated according to the equations (ISO, 1993):

$\operatorname{Max} \sigma(\mathrm{MPa})=\frac{F}{A}$

Table 1

Detailed composition of prepared films and respective colour parameters. The percentage of each additive is based on the initial chitosan mass. Films code: $\mathrm{C}$ (in the first position of the abbreviation) - CBC; C (in the second position of the abbreviation) - cellulose; S - silicone; E - extract; G - glycerol. Results are expressed as mean \pm SD.

\begin{tabular}{|c|c|c|c|c|c|c|c|c|c|c|c|c|}
\hline $\begin{array}{l}\text { Film } \\
\text { code }\end{array}$ & $\begin{array}{l}\mathrm{CBC}(\mathrm{mg} / \\
\mathrm{mL})^{* *}\end{array}$ & $\begin{array}{l}\text { Cellulose (\% } \\
\text { w/ w) }\end{array}$ & $\begin{array}{l}\text { Silicone (\% } \\
\mathrm{w} / \mathrm{w})\end{array}$ & $\begin{array}{l}\text { Glycerol (\% } \\
\text { w/w) }\end{array}$ & $\begin{array}{l}\text { Stump extract } \\
(\% \mathrm{w} / \mathrm{w})\end{array}$ & $L^{*}$ & $a^{*}$ & $b^{*}$ & $\begin{array}{l}\text { Hue } \\
\text { angle }\end{array}$ & Chroma & $\Delta \mathrm{E}$ & $\Delta \mathrm{H}$ \\
\hline C & 10 & - & - & - & - & $\begin{array}{l}96.6 \pm \\
0.6\end{array}$ & $\begin{array}{l}-0.9 \pm \\
0.1\end{array}$ & $\begin{array}{l}4.2 \pm \\
0.4\end{array}$ & $\begin{array}{l}-78.0 \pm \\
1.3\end{array}$ & $4.3 \pm 0.4$ & - & - \\
\hline CC & 10 & 10 & - & - & - & $\begin{array}{l}96.3 \pm \\
0.5\end{array}$ & $\begin{array}{l}-1.0 \pm \\
0.2\end{array}$ & $\begin{array}{l}4.9 \pm \\
0.2\end{array}$ & $\begin{array}{l}-78.5 \pm \\
1.9\end{array}$ & $5.0 \pm 0.3$ & $\begin{array}{l}0.9 \pm \\
0.3\end{array}$ & $\begin{array}{l}0.8 \pm \\
0.3\end{array}$ \\
\hline CS & 10 & - & 10 & - & - & $\begin{array}{l}96.5 \pm \\
0.7\end{array}$ & $\begin{array}{l}-1.0 \pm \\
0.2\end{array}$ & $\begin{array}{l}4.4 \pm \\
0.4\end{array}$ & $\begin{array}{l}-76.9 \pm \\
1.7\end{array}$ & $4.5 \pm 0.4$ & $\begin{array}{l}0.7 \pm \\
0.5\end{array}$ & $\begin{array}{l}0.2 \pm \\
0.1\end{array}$ \\
\hline CCS & 10 & 10 & 10 & - & - & $\begin{array}{l}96.1 \pm \\
0.6\end{array}$ & $\begin{array}{l}-1.1 \pm \\
0.2\end{array}$ & $\begin{array}{l}5.1 \pm \\
0.4\end{array}$ & $\begin{array}{l}-78.3 \pm \\
1.6\end{array}$ & $5.2 \pm 0.4$ & $\begin{array}{l}1.2 \pm \\
0.5\end{array}$ & $\begin{array}{l}0.2 \pm \\
0.1\end{array}$ \\
\hline $\mathrm{CE}$ & 10 & - & - & - & 10 & $\begin{array}{l}66.1 \pm \\
0.9\end{array}$ & $\begin{array}{l}4.7 \pm \\
0.6\end{array}$ & $\begin{array}{l}21.9 \pm \\
1.1\end{array}$ & $\begin{array}{l}77.8 \pm \\
2.1\end{array}$ & $\begin{array}{l}22.4 \pm \\
0.9\end{array}$ & $\begin{array}{l}35.7 \pm \\
0.4\end{array}$ & $\begin{array}{l}4.1 \pm \\
0.3\end{array}$ \\
\hline CCE & 10 & 10 & - & - & 10 & $\begin{array}{l}70.3 \pm \\
1.5\end{array}$ & $\begin{array}{l}3.8 \pm \\
0.3\end{array}$ & $\begin{array}{l}22.3 \pm \\
1.2\end{array}$ & $\begin{array}{l}80.3 \pm \\
0.5\end{array}$ & $\begin{array}{l}22.6 \pm \\
1.3\end{array}$ & $\begin{array}{l}32.3 \pm \\
2.0\end{array}$ & $\begin{array}{l}3.7 \pm \\
0.2\end{array}$ \\
\hline CCSE & 10 & 10 & 10 & - & 10 & $\begin{array}{l}66.6 \pm \\
2.9\end{array}$ & $\begin{array}{l}4.6 \pm \\
0.9\end{array}$ & $\begin{array}{l}19.2 \pm \\
1.3\end{array}$ & $\begin{array}{l}76.4 \pm \\
2.2\end{array}$ & $\begin{array}{l}19.8 \pm \\
1.3\end{array}$ & $\begin{array}{l}34.0 \pm \\
3.0\end{array}$ & $\begin{array}{l}4.1 \pm \\
0.4\end{array}$ \\
\hline CG & 10 & - & - & 20 & - & $\begin{array}{l}95.6 \pm \\
0.6\end{array}$ & $\begin{array}{l}-1.0 \pm \\
0.2\end{array}$ & $\begin{array}{l}4.9 \pm \\
0.2\end{array}$ & $\begin{array}{l}-78.6 \pm \\
2.1\end{array}$ & $5.0 \pm 0.2$ & $\begin{array}{l}1.3 \pm \\
0.3\end{array}$ & $\begin{array}{l}0.1 \pm \\
0.1\end{array}$ \\
\hline CCG & 10 & 10 & - & 20 & - & $\begin{array}{l}96.7 \pm \\
0.2\end{array}$ & $\begin{array}{l}-1.0 \pm \\
0.2\end{array}$ & $\begin{array}{l}4.4 \pm \\
0.2\end{array}$ & $\begin{array}{l}-76.6 \pm \\
1.9\end{array}$ & $4.5 \pm 0.2$ & $\begin{array}{l}0.4 \pm \\
0.2\end{array}$ & $\begin{array}{l}0.2 \pm \\
0.1\end{array}$ \\
\hline CGE & 10 & - & - & 20 & 10 & $\begin{array}{l}72.4 \pm \\
0.9\end{array}$ & $\begin{array}{l}3.5 \pm \\
0.4\end{array}$ & $\begin{array}{l}25.1 \pm \\
0.8\end{array}$ & $\begin{array}{l}81.9 \pm \\
1.1\end{array}$ & $\begin{array}{l}25.3 \pm \\
0.8\end{array}$ & $\begin{array}{l}32.3 \pm \\
0.9\end{array}$ & $\begin{array}{l}3.6 \pm \\
0.2\end{array}$ \\
\hline CCGE & 10 & 10 & - & 20 & 10 & $\begin{array}{l}76.2 \pm \\
0.1\end{array}$ & $\begin{array}{l}2.6 \pm \\
0.2\end{array}$ & $\begin{array}{l}24.4 \pm \\
0.4\end{array}$ & $\begin{array}{l}84.0 \pm \\
0.5\end{array}$ & $\begin{array}{l}25.5 \pm \\
0.4\end{array}$ & $\begin{array}{l}29.0 \pm \\
0.2\end{array}$ & $\begin{array}{l}3.2 \pm \\
0.1\end{array}$ \\
\hline
\end{tabular}

\footnotetext{
* approximate value of CBC concentration, calculated by weight measurements.
} 
where Max $\sigma$ is the maximum tensile stress sustained by the test film during a tensile test, in MPa; $\mathrm{F}$ is the measured force concerned, in N; and $\mathrm{A}$ is the initial cross-sectional area of the sample, expressed in $\mathrm{mm}^{2}$;

$\varepsilon(\%)=\frac{\Delta L}{L_{0}} \times 100$

where $\varepsilon$ is the tensile strain at the tensile stress at break, in percentage; the $\Delta \mathrm{L}$ is the increase in the sample length between the grips, expressed in $\mathrm{mm}$; and the $\mathrm{L}_{0}$ is the initial length of the sample, also in $\mathrm{mm}$.

The modulus of elasticity (Young's Modulus, E') was defined as the slope of linear section of the Max $\sigma$ versus $\varepsilon$ curve, being expressed in MPa.

\subsection{Attenuated total reflection - Fourier-transform infrared spectroscopy (ATR-FTIR)}

In order to investigate the main chemical groups and the interactions of $\mathrm{CBC}$ with the additional components of the films, ATR-FTIR spectroscopy was carried out (Perkin Elmer, FTIR/NIR spectrophotometer, Universal ATR sampling accessory, UK). The experiments were performed at 128 scans with $4 \mathrm{~cm}^{-1}$ resolution, between 500 and 4000 $\mathrm{cm}^{-1}$, and the PerkinElmer spectrum software was used.

\subsection{Thermogravimetric analysis (DSC/TGA)}

Water content and the presence of films' components were analysed by simultaneous thermal analyser (differential scanning calorimetry/ thermogravimetric analysis, DSC/TGA, TA Instruments, model Q600, USA), in duplicate. Small portions of films (6-12 mg) were heated at 10 ${ }^{\circ} \mathrm{C} / \mathrm{min}$, from $25^{\circ} \mathrm{C}$ up to $600{ }^{\circ} \mathrm{C}$, under a nitrogen atmosphere $(100 \mathrm{~mL} /$ $\mathrm{min}$ ). Moisture content of films was determined based on weight loss before $100{ }^{\circ} \mathrm{C}$. The presence of cellulose, silicone, glycerol, or pine extract were inferred based on the respective melting/boiling points and/or degradation temperatures. These pure compounds were also analysed by this technique.

\subsection{Scanning electron microscopy (SEM)}

Morphology/surface appearance of CBC films were determined by SEM using a TESCAN Vega 3 SBH (Czech Republic) electron microscope at HV $5.0 \mathrm{kV}$. The samples were fixed in an adequate stub using a doublesided adhesive tape, and sputtered with a mixture of gold/palladium during $30 \mathrm{~s}$ (10 $\mathrm{nm}$ layer) in argon atmosphere.

\subsection{Water vapour sorption and transmission rate}

The most promising films to obtain an active food packaging system with good mechanical properties were also evaluated in terms of water vapour sorption and transmission rate, at least in triplicate. Therefore, films with glycerol and/ or pine extract were selected (Table 1).

Samples were cut into $1 \mathrm{~cm}$ squares and fixed onto opening of permeability cells $\left(6.36 \times 10^{-5} \mathrm{~m}^{2}\right.$ circular area/aperture of exposition to water vapour), filled with silica gel. These systems were dried at $40{ }^{\circ} \mathrm{C}$ for $48 \mathrm{~h}$, until constant weight was achieved, and placed inside sealed glass chambers filled with a saturated solution of $\mathrm{K}_{2} \mathrm{SO}_{4}$ to promote an equilibrium relative humidity of $97 \%$. These systems were maintained at $25{ }^{\circ} \mathrm{C}$, and weighed at pre-determined time points for 7 days. After saturation (steady state) of films, daily water vapour transmission rate (WVTR) across the films was analysed, and calculated according to the equation (Pires et al., 2018):

$\operatorname{WVTR}\left(\mathrm{g} / \mathrm{m}^{2}\right.$ day $)=\left(\frac{\Delta w}{A}\right)$

where $\Delta \mathrm{w}$ (g/day) is the weight difference of the cells, and $\mathrm{A}\left(\mathrm{m}^{2}\right)$ is the area of the film in contact with the water vapour.
Water vapour sorption (WVS, \%) capacity was calculated, based on the initial weight of dried film samples $(1 \mathrm{~cm} \times 1 \mathrm{~cm})$ and wet films (after complete saturation of the film) (Suesca et al., 2017; Vlacha et al., 2016).

\subsection{In vitro cytotoxicity}

Cytotoxicity evaluation of the films was performed to infer about possible toxicity for human health, namely if there is the possibility of developing edible films. Mouse fibroblasts NCTC clone 929 cell line were used, and the most promising films in terms of mechanical properties and antioxidant activity were tested, similarly to the water vapour assays. Therefore, films containing glycerol and/or the pine extract (with and without cellulose) were chosen (Table 1). Pure CBC films were used as the control, and to infer about this polymer toxicity. Additionally, individual films components' cytotoxicity was also evaluated. Glycerol and pine stump extract were tested at a concentration similar to the maximum value they have in the films. Chitosan (used to produce $\mathrm{CBC}$ ) and cellulose were not assessed, since they were not possible to dissolve in conventional solvents compatible with cell growth. Due to the nature and shape of the films, the assays were carried out following a preparation of a leachate of the samples, as described in ISO $10993-12$ (ISO, 2004). In summary, the samples were sterilized for $1 \mathrm{~h}$ under UV radiation, immersed in minimum essential medium (MEM), supplemented with $1 \%$ non-essential amino acids (NEAA) and $0.5 \%$ heat-inactivated fetal bovine serum (FBS) according to the concentrations described in ISO $10993-12(0.1 \mathrm{~g}$ of film per $\mathrm{mL}$ of culture media). The leaching proceeded at $37 \pm 1{ }^{\circ} \mathrm{C}$ for $24 \pm 2 \mathrm{~h}$ under magnetic stirring.

Mouse fibroblasts NCTC clone 929 were cultured according to the ISO 10993-5 (ISO, 2009) for Biological evaluation of medical devices, in a standard medium MEM supplemented with $1 \%$ NEAA and $10 \%$ heat-inactivated FBS at $37{ }^{\circ} \mathrm{C}$ with $5 \% \mathrm{CO}_{2}$ in a humidified incubator (Nuaire, USA), routinely grown as a monolayer in $75 \mathrm{~cm}^{2}$ culture flasks.

Cytotoxicity was assessed following ISO 10993-5 (ISO, 2009) with slight modifications. Briefly, cells were seeded into 96-well plates with a density of $3 \times 10^{4}$ cells $/ \mathrm{cm}^{2}$ and maintained in culture for $24 \mathrm{~h}(\sim 1$ doubling period) to form a semi-confluent monolayer. Cells were incubated with the leachates diluted in culture medium (MEM supplemented with $0.5 \%$ FBS). The highest concentration tested was the pure leachate and the following concentrations were achieved using successive dilutions of 1:2. After $24 \mathrm{~h}$ of incubation, the culture media was discarded, cells washed twice with phosphate buffered saline (PBS) and incubated for $3 \mathrm{~h}$ with CellTiter $96 \AA$ Aqueous Non-Radioactive Cell Proliferation Assay (MTS) reagent assay, diluted according to the manufacturer's information. Absorbance was measured at $490 \mathrm{~nm}$ in a microplate spectrophotometer (BioTek Epoch ${ }^{\mathrm{TM}} 2$ Microplate Spectrophotometer, USA). Cell viability was expressed in terms of percentage of living cells relatively to the negative control (cells incubated only with culture media). DMSO solution ( $10 \%, \mathrm{v} / \mathrm{v}$ ) diluted in MEM was used as positive control of cytotoxicity. Three independent experiments were performed in triplicate.

All data is expressed as mean \pm standard deviation (SD). GraphPad Prism 6 software was used to calculate half maximal inhibitory concentration values $\left(\mathrm{IC}_{50}\right)$, the concentration of leachate necessary to decrease $50 \%$ of cell population.

\section{Results and discussion}

Results from the obtained $\mathrm{CBC}$ films with distinct compositions (Table 1) are discussed, regarding their physicochemical properties and cytotoxicity.

\subsection{Thickness}

Films showed thickness in the 55-70 $\mu \mathrm{m}$ (mean values) range. These 
values are in accordance with the thickness close to $60 \mu \mathrm{m}$ of other polymeric films for food packaging applications [17, 18]. The highest values corresponded to the extract-loaded films containing glycerol (CGE and CCGE, Fig. 1I). Control films (pure CBC) correspond to those with the lowest thickness values, as expected. Slightly higher values were achieved for formulations containing an additive (cellulose, silicone, glycerol, extract), as observed in other works (Mujtaba et al., 2019; Pires et al., 2018). Slight thickness differences were observed between other films, with varied compositions.

\subsection{Water contact angle}

Fig. 1II contains water contact angles data measured for all CBC films. Values between $84.2 \pm 6.4^{\circ}$ and $102.1 \pm 5.0^{\circ}$ were reached, with most of films having values close to hydrophobic "zone" (values lower than but close to $90^{\circ}$ ). This range of water contact values is in accordance with those obtained with other materials usually used for food packaging (e.g. 76-100 ${ }^{\circ}$ for PET) (Meiron and Saguy, 2007).

The addition of cellulose and silicone increased the hydrophobicity of the film surface, and therefore the water contact angles, which were higher than $90^{\circ}$ (associated to hydrophobic surfaces). Furthermore, for CBC films with silicone (CS, CCS and CCSE), the highest values $\left(>90^{\circ}\right)$ of water contact angle were achieved. This is in accordance with previous works, where angles of about $100^{\circ}$ were obtained for chitosanalginate films with $10 \%$ Silpuran ${ }^{\circledR} 2130 \mathrm{~A} / \mathrm{B}$, similarly to this work (Pires et al., 2018). Silicone coatings are in general water and oil repellent (Geueke, 2015) and therefore this explains the higher water contact angles that were observed. Cellulose presents low water affinity and that property leads to higher values of water contact angles. On the other side, glycerol has slightly decreased the contact angle values, due to its hydrophilic nature. This property may confer some moisture content to the fresh food, which may be an advantage in preserving their
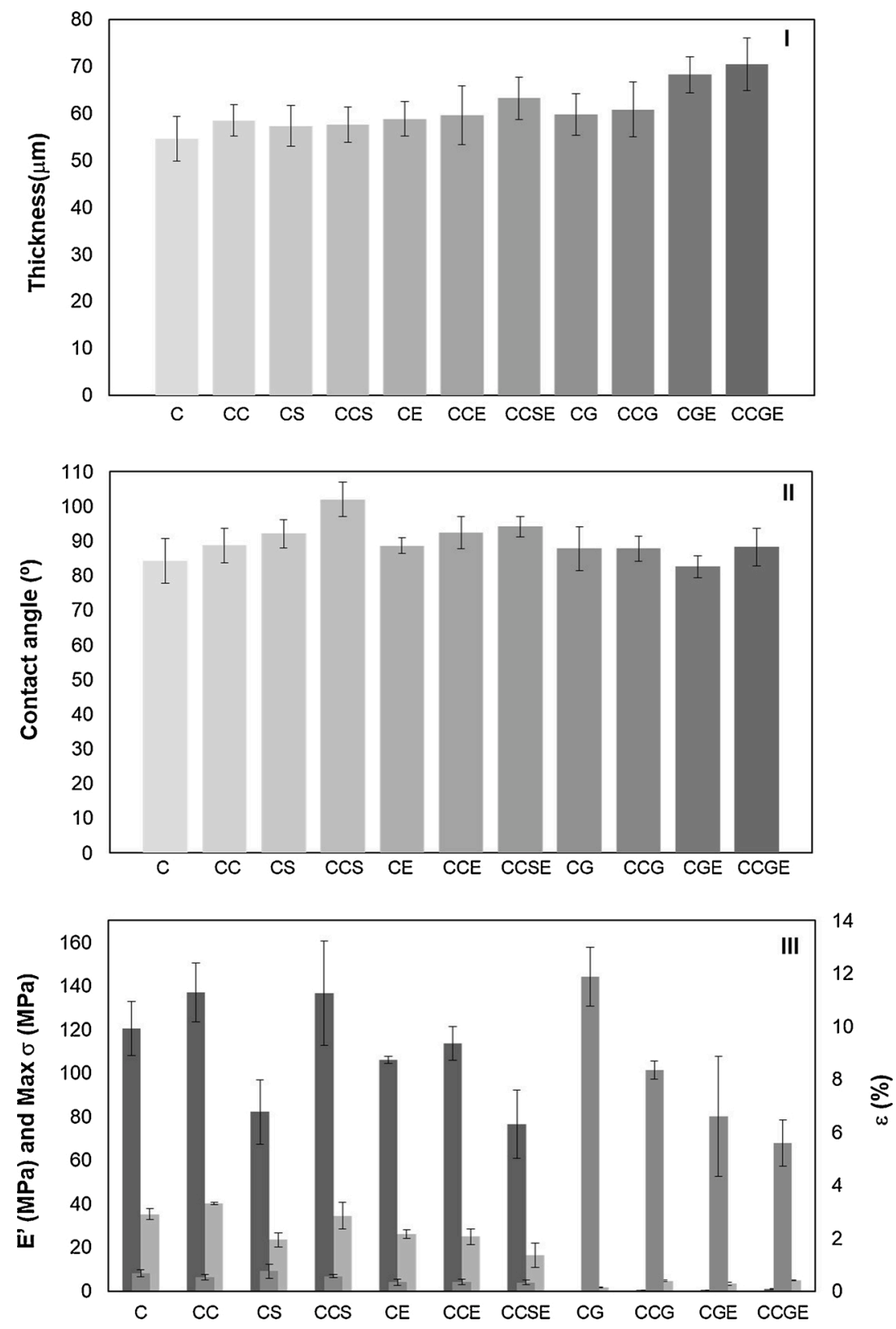

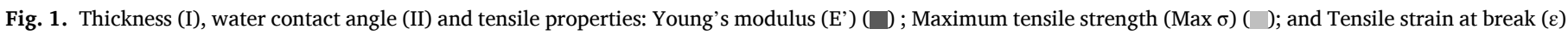

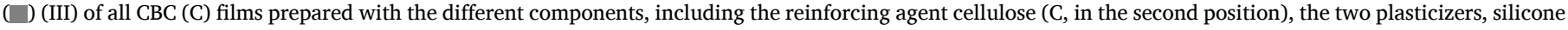
$(\mathrm{S})$ and glycerol $(\mathrm{G})$, and the pine extract (E). Results are expressed as mean $\pm \mathrm{SD}$. 
characteristics. This affinity to the water was also confirmed by the higher values of water vapour transmission rate and water vapour sorption (Section 5.8). Glycerol is also soluble in water, being widely used in food packaging applications (Pagliaro and Rossi, 2008).

\subsection{Colour}

Films colour was determined since it is a critical feature of a food packaging system, because it can have a preservative function, by reducing the photo-oxidation, and may impact the consumer choice (Muxika et al., 2018; Ren et al., 2017). The results of colour measurements for all CBC films are included in Table 1. CBC pure films had, in general, colour parameters similar to previous works (Pires et al., 2018). $\mathrm{L}^{*}$ parameter, which is related to lightness, is close to 100 in films without the extract meaning that they are almost transparent/clear. For those with the extract, some opacity is observed with $\mathrm{L}^{*}$ values around 70. Regarding chromaticity coordinates $a^{*}$ and $b^{*}$, positive values of $a^{*}$ were achieved for films with the pine extract, while the others had negative values. Thus, the addition of pine stump extract moved this parameter to the red direction. For $b *$ values, an increment from $\sim 5-20$ was observed by the addition of the extract, increasing the yellow saturation. Hue angle was $\sim 80$ for films with the antioxidant extract, and $\sim-80$ for films without the extract, while chroma was in the $20-25$ range for extract-loaded films and between 4 and 5 for unloaded films. Colour difference $(\Delta \mathrm{E})$ for films loaded with the extract is around 30 and for tonality difference $(\Delta \mathrm{H})$ it is close to 4 , values that are much higher than for films without the extract. The colour parameters of films with remaining additives (cellulose, glycerol or silicone) apparently did not differ from those of pure CBC films.

Therefore, the major differences in colour were observed for films loaded with the extract. In fact, for the extract-loaded films, a brown colour, and some degree of opacity were visually detected (Fig. S1 III), compared with the pure CBC films (Fig. S1 II). Therefore, these systems may have the potential to protect food from the UV radiation, by decreasing photo-oxidation, as observed in other studies (Souza et al., 2017). Similar brownish colour was found by other researchers for edible films with grape seed extract (Atarés and Chiralt, 2016). Other researchers found some extracts that affected the transmittance of light in chitosan films, leading to improved light barrier and therefore an extra protective shield against oxidative processes (Souza, Fernando et al. 2017).

Composite films with chitosan and antioxidant compounds showed lower light transmission (Liu et al., 2017).

\subsection{Mechanical properties}

Average maximum tensile strength (Max $\sigma$ ), tensile strain at break $(\varepsilon)$ and Young's Modulus (E') measured for all films are included in Fig. 1 III. Tensile strength is the maximum tensile stress sustained by the film during the tensile test; the Young's modulus indicates the rigidity of the film (a smaller E' corresponds to a more flexible sample); and the tensile strain at break is related to the film flexibility and elongation capacity, and is determined at the film break point under tensile testing (ISO, 1993; Ren et al., 2017).

Values of 0.1-137 MPa were obtained for the Young's modulus, while for maximum tensile strength, values were in the 1.7-10 MPa range. The highest values of these two mechanical parameters were observed for films without glycerol (between 76 and $137 \mathrm{MPa}$ for E', and 16-40 MPa for Max $\sigma$ ). The tensile strain at break varied from $0.3-12 \%$. There is a clear difference between films that include glycerol and those without this plasticizer. Young's modulus for films with glycerol were in the 0.1-1.0 MPa range, indicating higher elasticity of these samples, and tensile strength was between 1.7 and 4.8 MPa, revealing the lower stress supported by these films. For films with glycerol, higher values of tensile strain at break $(\varepsilon)$ were attained (5.6-11.9\%), being in accordance with E' values and reflecting the flexibility and elongation ability of these formulations. Opposite $\varepsilon$ results were observed for films without glycerol $(0.3-0.8 \%)$.

Mechanical properties were, in general, enhanced by the addition of glycerol, and its use tends to desirably alter the tensile strength and elongation properties at break, as well as to decrease the moisture barrier of materials (Vlacha et al., 2016). The action of this plasticizer consists in causing changes in the polymer network, with consequent increase of flexibility and reduction of the tensile strength of the films (Moreira Gonçalves et al., 2020). Moreover, the increased flexibility of films with glycerol may be due to the interaction of plasticizer-polymer chains which facilitates the sliding of chain and therefore improves the overall flexibility and chain mobility (Farahnaky et al., 2013; Mujtaba et al., 2019; Ren et al., 2017; Vlacha et al. 2016).

Cellulose increased Young's modulus and maximum tensile strength, conferring higher rigidity to the respective films, Fig. 1 III (namely those made of CBC plus cellulose). Cellulosic fibres have been already used as a reinforcement agent, to improve mechanical performance of packages (Müller et al., 2009).

The addition of silicone has slightly increased elasticity (Fig. 1 III, $\mathrm{CS}$ ). According to previous studies by other researchers, the addition of Silpuran ${ }^{\circledR} 2130$ A/B may increase stiffness of formulations (Bombaldi de Souza et al., 2016). In other works, the incorporation of silicon carbide nanocomposites in chitosan composite films increases the tensile strength (Pradhan et al., 2015). However, in this work some difficulty in dispersing the silicone was noticed, resulting in a non-homogenous film structure.

In general, the addition of extract tends to reduce the film elasticity (which is more pronounced in films CGE and CCGE with the reduction of tensile strain at break), but it is essential for the antioxidant activity of the packaging. The addition of several essential oils (ginger, rosemary, thyme, etc.) in other works have revealed increments in mechanical properties of chitosan films (Souza et al., 2017). This is in contrast to these results, and it is probably due to the aqueous nature of the pine stump extract that was used, contrary to the hydrophobic properties of the essential oils.

Mechanical properties of the obtained films are somewhat close to the values observed by other authors for packaging chitosan films, containing agroindustrial residue extracts, with tensile strength of $16-19 \mathrm{MPa}$, tensile strain close to $20 \%$, and Young's modulus $\sim 100$ MPa (Serrano-León et al., 2018).

Variations in mechanical results can be the consequence of many factors, namely composition, film preparation, presence of plasticizer and its concentration, degree of deacetylation, among others (Ziani et al., 2008). Low tensile strength found for some films may be ascribed to insufficient formation of entanglement networks. Films that consist in a matrix with larger interstitial space may correspond to harder films and higher film thickness (Souza et al., 2013).

\subsection{ATR-FTIR}

ATR-FTIR experiments were conducted to confirm the structure/ incorporation of distinct compounds in the CBC films, and to infer about possible structural interactions between $\mathrm{CBC}$ and other films' components. Complete FTIR data is included in Fig. S2 (Supplementary material). For CBC polymer (all films), several bands were observed between 1300 and $1800 \mathrm{~cm}^{-1}$. Characteristic bands of substituted amino groups are located in the $1400-1800 \mathrm{~cm}^{-1}$ range (Dias et al., 2011), and peaks at $1640,1550,1375$, and $1307 \mathrm{~cm}^{-1}$ were identified. According to literature, peaks around 1700,1400 and $1310 \mathrm{~cm}^{-1}$ correspond to many $\mathrm{C}=\mathrm{O}$ stretching modes of the carbonyl groups and around $1550 \mathrm{~cm}^{-1}$ to the $\mathrm{NH}$ - bending mode of CBC amide II groups (Dias et al. 2011). Bands observed at 1025 and $1063 \mathrm{~cm}^{-1}$ may be assigned to $\mathrm{C}-\mathrm{O}$ stretching and $\mathrm{O}-\mathrm{H}$ deformation vibrations from the hydroxyl groups of $\mathrm{CBC}$.

For glycerol, and films with this plasticizer, two main peaks were observed: a wide band at $3293 \mathrm{~cm}^{-1}$, and an intense peak at $1029 \mathrm{~cm}^{-1}$, which may be attributed to free $-\mathrm{OH}$ stretching and to $\mathrm{C}-\mathrm{O}$ stretching 
or $\mathrm{O}-\mathrm{H}$ deformation vibrations, respectively. The peaks at 2880 and $2935 \mathrm{~cm}^{-1}$ are attributed to axial deformation of $\mathrm{C}-\mathrm{H}$ bonds in $\mathrm{CH}_{2}$ from the alkyl chain (common to many organic substances), as reported by other authors that found these peaks at 2925 and $2852 \mathrm{~cm}^{-1}$ (Guimarães et al., 2016).

Regarding cellulose and respective films, a peak at $895 \mathrm{~cm}^{-1}$ was observed, which corresponds to $\beta$-glycoside linkages in cellulose structure. The peak at $665 \mathrm{~cm}^{-1}$ may be assigned to $\mathrm{O}-\mathrm{H}$ vibrations since peaks between 800 and $650 \mathrm{~cm}^{-1}$ have already been attributed to that vibrations by other authors (Mujtaba et al., 2017). Peaks at 1023 and $1054 \mathrm{~cm}^{-1}$ may be attributed to stretching modes of cellulose in the CBC matrix, since in other works this stretching behaviour corresponded to peaks at 1022 and $991 \mathrm{~cm}^{-1}$ and associated to cellulose crystals in chitosan matrix (Mujtaba et al., 2017).

Silicone (Silpuran ${ }^{\circledR} 2130$ A/B) showed three main peaks, at 1258 , 1009 and $787 \mathrm{~cm}^{-1}$, which were also observed in the films containing silicone. According to other works, Silpuran ${ }^{\circledR} 2130$ A/B usually presents peaks at $1260 \mathrm{~cm}^{-1}$ that corresponds to $\mathrm{Si}-\mathrm{CH}_{3}$ stretch and at 1090 and $1020 \mathrm{~cm}^{-1}$, corresponding to $\mathrm{Si}-\mathrm{O}-\mathrm{Si}$ stretch (Pires et al., 2018), being in agreement with the present results. Some of silicone bands were not clearly observed in the respective films because in the $1000-1060 \mathrm{~cm}^{-1}$ region there is overlapping of silicone peaks with $\mathrm{CBC}$ peaks, and in some formulations with cellulose and/or glycerol bands.

No specific or intense peak was observed for spectrum of pine extract probably due to its complex composition, but its presence in the CBC films is easily confirmed by visual inspection and colour analysis. Only one peak $\sim 800 \mathrm{~cm}^{-1}$ appears to be present in the films with the extract. However, there is no clear evidence of new formed chemical groups, from the possible interaction between $\mathrm{CBC}$ and other films' components.

\subsection{Thermogravimetric analysis}

Water content and the presence of compounds in each formulation was determined by thermogravimetric assays. The main results are included in Fig. 2.

Water was present in $\sim 10-20 \%(\mathrm{w} / \mathrm{w})$, as denoted by the peak accompanied by weight loss, around $60-70{ }^{\circ} \mathrm{C}$. These results are in agreement with other works presenting moisture content of about $20 \%$ for chitosan films containing agro-industrial residue extracts (determined by gravimetric analysis) (Serrano-León et al., 2018). CBC degradation was observed close to $300{ }^{\circ} \mathrm{C}$ for all films. Extract degradation occurred at the same temperature, being therefore difficult to confirm the presence of the extract in the films by this technique. However, due to other analyses and to the brown colour of the extract, there is no doubt about the extract incorporation in the films. Presence of glycerol, cellulose and silicone were also confirmed in the CBC matrix, because the respective peaks were observed. Glycerol showed boiling point close to $200{ }^{\circ} \mathrm{C}$, with $100 \%$ weight loss, according to literature (Mujtaba et al., 2017; Pagliaro and Rossi, 2008), and this peak was observed in the CBC films containing this plasticizer. Cellulose had a characteristic peak around $350{ }^{\circ} \mathrm{C}$, which probably corresponded to its structural degradation, as already reported by other authors (Mujtaba et al., 2017), with a weight loss higher than $80 \%$, being this peak observed in the films containing cellulose. Silicone (Silpuran ${ }^{\circledR} 2130$ A/B) appears to start to decompose close to $500{ }^{\circ} \mathrm{C}$, and this peak was also present in the respective films.

\subsection{Scanning electron microscopy (SEM)}

Films morphology was inspected by SEM, namely for their microstructure analysis. Some of films micrographs are included in Fig. 3.

In general, films were smooth in SEM analysis, with compact structures and those with cellulose, and/or including pine extract revealed some degree of roughness and/or some grains on the surface (C, CE, CCSE).

The smoothest films corresponded to the films with glycerol or silicone (CG and CS). The smoothest films should also correspond to the highest Young's modulus, according to findings from other works (Farahnaky et al., 2013; Ren et al., 2017). However, for films with glycerol/silicone, this was not observed in Fig. 1 III. According to the literature, the homogenous matrix is related to the structural integrity of the films, and mechanical properties (Farahnaky et al., 2013; Ren et al., 2017). In this work, glycerol increased, in general, the mechanical properties, with more flexible films, and silicone has slightly improved elasticity of respective films. Moreover, for CBC films with silicone (CS), small "hollows/droplets" were observed, which are attributed to the hydrophobic nature of silicone and is in accordance with previous findings for films with Silpuran ${ }^{\circledR} 2130$ A/B (Pires et al., 2018).

In films with extract, but without glycerol some cracks were observed in SEM analysis (CE and CCSE). This may be related to the lower mechanical properties obtained for these formulations, probably based on the heterogeneity of the films generated by film casting manufacturing process.

\subsection{Water vapour sorption and transmission rate}

Water vapour sorption (WVS) and transmission rate (WVTR) properties of films are important since films should act as a barrier to reduce humidity exchange between the packaged food and the adjacent atmosphere (Ren et al., 2017). Films with the most adequate mechanical properties and biodegradable characteristics (with glycerol) were selected for these assays.

Main results related to the water vapour sorption and transmission rate are included in Table 2. For WVTR (calculated at steady state, after films saturation at $24 \mathrm{~h}$ ), mean values between $\sim 981$ and $1142 \mathrm{~g} / \mathrm{m}^{2}$ day were achieved, while WVS was in the $47-54 \%$ range. These WVTR values are close to previous works that showed values of $755 \mathrm{~g} / \mathrm{m}^{2}$ day for chitosan-alginate films (Pires et al., 2018). Comparison with CBC films from the literature is more difficult since there is scarce of data related to films with this chitosan-derivative, and respective characterisation. However, some authors reported WVS of CBC films in the 40-50 $\%$ range (Dias et al., 2011), values close to those achieved in this work.

Glycerol has slightly increased the WVTR, and the WVS, when comparing with the pure CBC film. According to other authors, an increment in the WVTR was noticed due to the glycerol addition in films (Gontard et al., 1993). Moreover, the type and concentration of plasticizer can cause modifications in the barrier properties of polymeric films (Moreira Gonçalves et al., 2020). It would be expected to achieve lower WVTR for films with the plasticizer. However, some controversial results may be obtained due to micro-cracks in the films (Farahnaky et al., 2013) or to reduced intermolecular attractions of the polymer (due to the small hydrophilic glycerol molecule that can be inserted between polymeric chains). Therefore, water migration may be facilitated, increasing the diffusion rate of water in the films (Vlacha et al., 2016). In fact, matrices characterised with wide interstitial space may lead to an increased diffusion rate of water. Moreover, the larger the interstitial space, the greater the surface area and volume available for adsorption of water molecules (Souza et al., 2013).

The pine stump extract has incremented WVTR mean values, but considering the standard deviation, values are close to those from films with glycerol. The highest values that were observed for films with the extract may be due to the cracks that were identified by the SEM analysis (Fig. 3), allowing more water molecules to pass through the film. This extract also appears to increase WVS values, and this is probably related to its aqueous nature. Distinct results related to the water sorption and transmission behaviour of films, after including some additives have already been achieved (Mujtaba et al., 2019). For example, the addition of the phenolic compound protocatechuic acid (Liu et al., 2017), or citronella essential oil and cedarwood oil (Shen and Kamdem, 2015) in chitosan films reduced the water vapour permeability. However, the inclusion of gallic acid in conjugated chitosan films increased the water vapour transmission rate, due to irregular surface structure (Rui et al., 

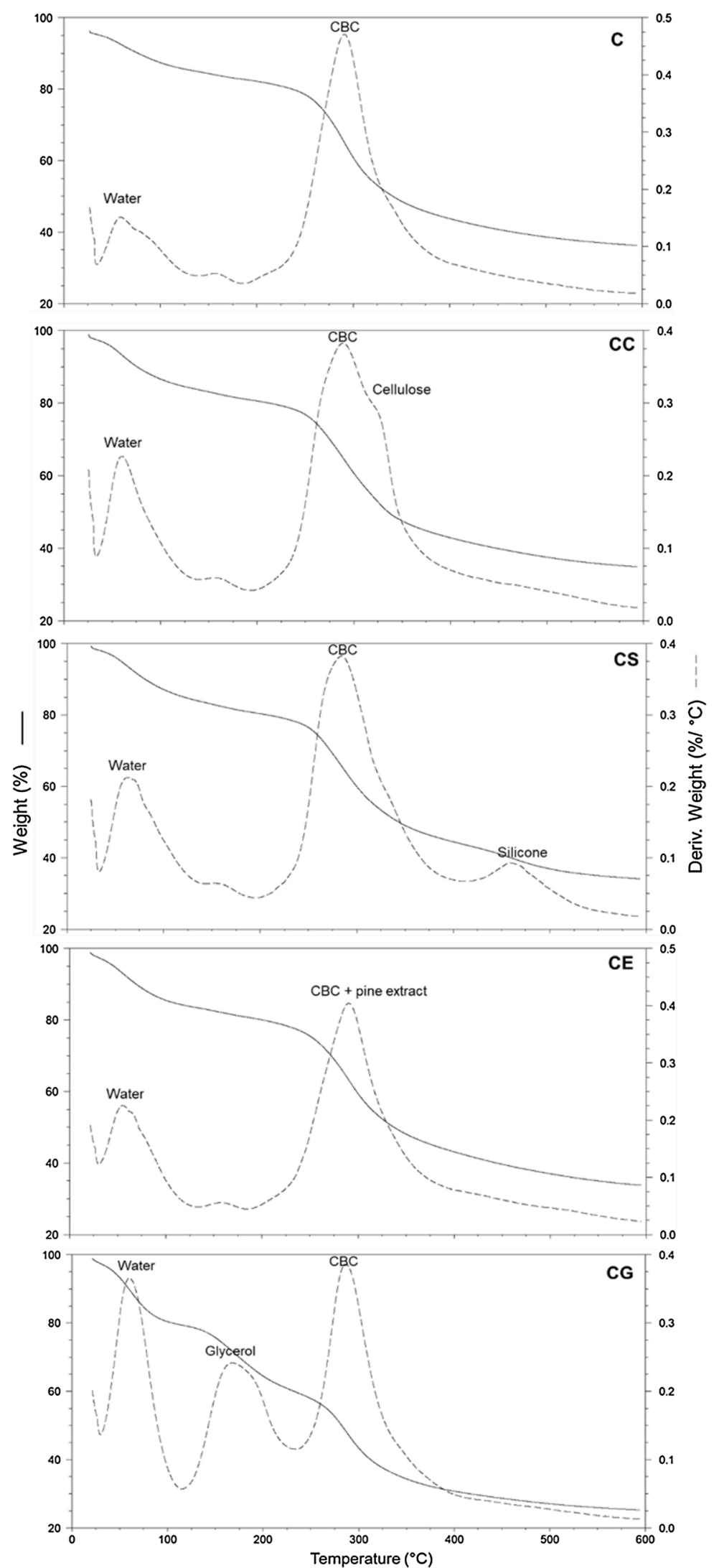

Fig. 2. Thermogravimetric properties of pure CBC films (C) and CBC films loaded with cellulose (CC), silicone (CS), pine stump extract (CE) or glycerol (CG). 

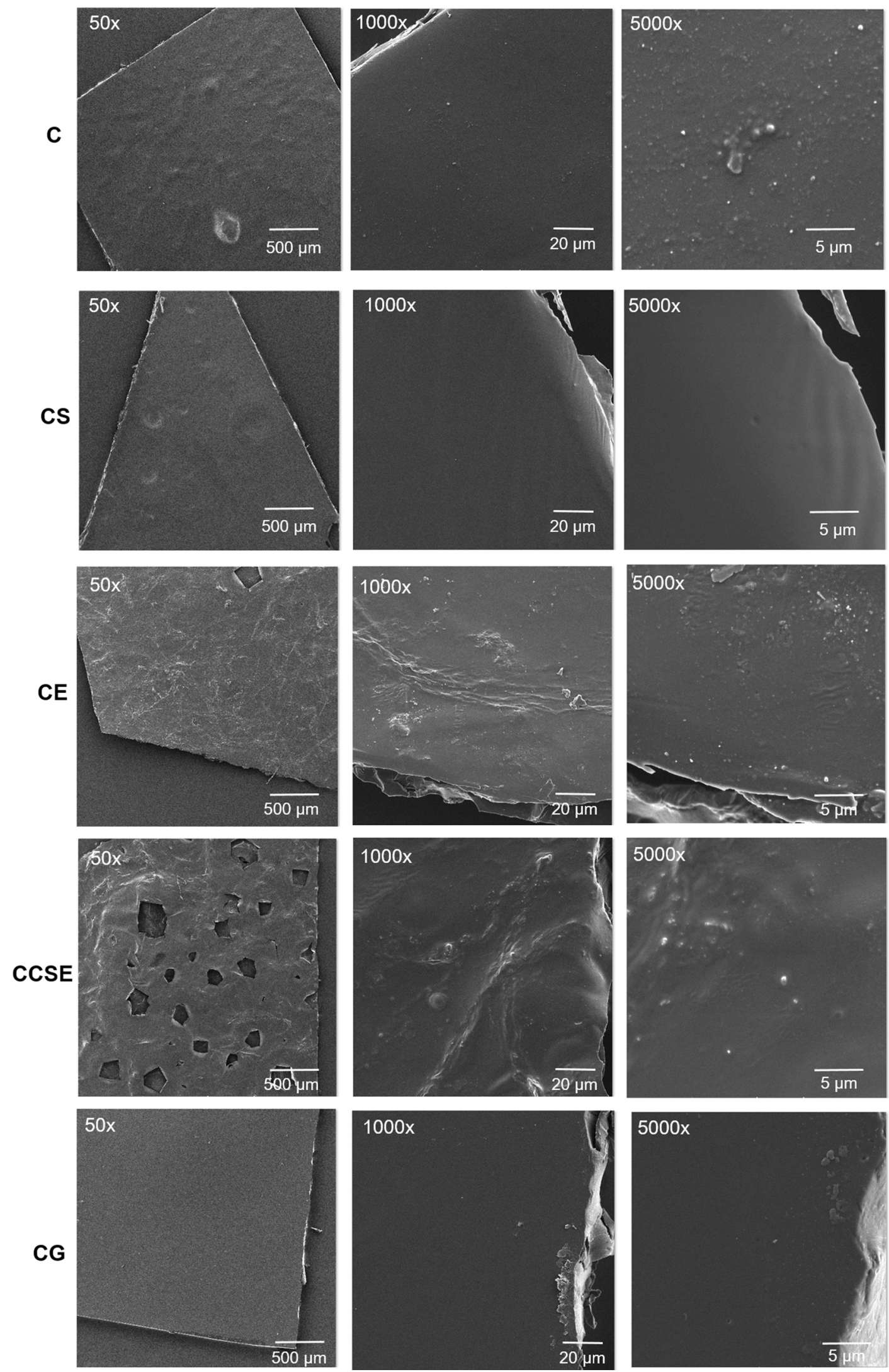

Fig. 3. SEM micrographs of some CBC films at $50 \times, 1000 \times$ and $5000 \times$ magnification. 
Table 2

Water vapour transmission rate and water vapour sorption of selected CBC films; and $\mathrm{IC}_{50}$ calculated for each film leachate and individual component tested. Results are expressed as mean \pm SD.

\begin{tabular}{llll}
\hline Film code & WVTR $\left(\mathrm{g} / \mathrm{m}^{2}\right.$ day $)$ & WVS $(\%)$ & Relative $\mathrm{IC}_{50}(\mathrm{mg} / \mathrm{mL})$ \\
\hline C & $980.9 \pm 61.3$ & $47.1 \pm 1.7$ & $66.5 \pm 4.9$ \\
CG & $1096.7 \pm 92.0$ & $52.1 \pm 1.1$ & $68.1 \pm 3.7$ \\
CCG & $1094.2 \pm 64.2$ & $50.1 \pm 1.9$ & $77.0 \pm 7.1$ \\
CGE & $1135.4 \pm 47.4$ & $53.8 \pm 1.6$ & $0.905 \pm 0.062$ \\
CCGE & $1142.5 \pm 36.3$ & $49.2 \pm 1.3$ & $1.57 \pm 0.076$ \\
Glycerol & n/a & n/a & Not determined \\
Pine stump extract & n/a & n/a & $0.0883 \pm 0.012$ \\
\hline
\end{tabular}

$\mathrm{n} / \mathrm{a}$ - not applicable.

2017). Chitosan films with olive pomace revealed better antioxidant activity but higher water transmission rate and poor mechanical properties (de Moraes Crizel et al., 2018).

On the other side, there is a small trend (in terms of mean values) for reduced WVS and WVTR, when cellulose is present in the films, and this result may be ascribed to its water-insoluble nature. In other works, no significant improvement was observed in water vapour barrier properties, when cellulose nanocrystals were added in chitosan films, due to overall lower film crystallinity (Mujtaba et al., 2017).

\subsection{In vitro cytotoxicity}

Cytotoxicity evaluation was performed using mouse fibroblasts NCTC clone 929 cell line.

It should be emphasised that Silpuran ${ }^{\circledR} 2130 \mathrm{~A} / \mathrm{B}$ was mainly used to have a comparator in terms of film properties, with glycerol. Nevertheless, this silicone is biocompatible and could eventually be used in packaging food applications since silicones are commonly used as food contact materials (Geueke, 2015). However, these polymers are very persistent to biological degradation, and therefore they should be used with caution. Taking into consideration that glycerol is eco-friendlier than silicone, and based on better mechanical properties showed by films with this plasticizer (Table 1, Fig. 1 III), these were chosen for the cytotoxicity assays (similarly to the water vapour studies). These cytotoxicity studies correspond to a first attempt to evaluate the possibility of using these films as edible food packaging systems.

Fig. 4 I shows the cytotoxicity profile obtained for the selected CBC films. Pure CBC films and CG and CCG films produced very fluid leachates with a light orange colour, in contrast to films with the extract (CGE and CCGE), that produced thicker leachates with a dark colour (due to the pine stump extract). Pure CBC films and those with glycerol and cellulose (CG and CCG) revealed cytotoxicity only at the highest concentration tested.

The formulations containing pine stump extract in their composition (CGE and CCGE) revealed cytotoxicity at almost all the dilutions tested. This suggests that the pine stump extract could be the cause of the cytotoxic effects of the films. The increase of the cell viability observed for the most concentrated samples could be possibly due to the remaining of some extract in the cells after the cell washing steps, that may interfere with the absorbance of MTS, due to the extract colour.

To understand which component induced the major cytotoxic effect to the films, individual films components' cytotoxicity was also evaluated, namely glycerol and pine stump extract.

Since glycerol and pine stump extract account, respectively, for $20 \%$ and $10 \%$ of the film in relation to the chitosan mass, this means $16.7 \%$, for glycerol, and $8.35 \%$, for the extract, of the total film mass. Once the total film used in the leaching was $0.1 \mathrm{~g} / \mathrm{mL}$, the maximum of each of these components that was possible to be leached in an optimal leaching process would be $0.0167 \mathrm{~g} / \mathrm{mL}$ for glycerol and $0.00835 \mathrm{~g} / \mathrm{mL}$ for pine stump extract. Thus, the maximum concentration tested in the cytotoxicity assays with glycerol and pine stump extract were 0.0167 and $0.00835 \mathrm{~g} / \mathrm{mL}$, respectively. Fig. 4 II shows the cytotoxicity obtained for these two components. These results, combined with those obtained from the films, suggest that the cytotoxicity observed for films with the extract are indeed derived from the pine stump extract itself, since the extract is highly toxic in almost all the concentrations tested and glycerol was not cytotoxic at all the concentrations assessed. Therefore, the lower cell viability observed at the highest concentration tested in the films with glycerol may be attributed to $\mathrm{CBC}$, or to the presence of sodium borohydride residues in the films.

Chitosan and cellulose were not tested due to their poor solubility. Nevertheless, chitosan is considered a non-toxic material (Haghighi et al., 2020). The IC 50 obtained for each sample are present in Table 2.

Although the composition and concentrations of the leachates tested in the cells are not fully known, all the samples showed some degree of cytotoxicity and therefore should be used with caution. These results suggest that when in contact with the culture media at $37^{\circ} \mathrm{C}$ for $24 \mathrm{~h}$, the films release compounds that are toxic to the cell line used in the assays. Films without extract revealed much lower cytotoxicity when compared to films with the pine extract. This cytotoxicity may be provided by the presence of pine stump extract in these films, which was confirmed by the cytotoxicity of the pine stump extract alone.

All films revealed lower $\mathrm{IC}_{50}$ values than the pine stump extract itself which may be due to some "protective" characteristic given by other component of the film.

CBC films with glycerol revealed to have low toxicity and may be used as edible films, while films with the extract should not be used as edible coatings in food packaging strategies, but may be used as films in packages that need protection against oxidation. However, additional strategies should be applied to further study the cytotoxicity of these materials, namely with other cell lines and with a strategy where the real concentration that is used in the cells is possible to determine, in order to calculate an absolute $\mathrm{IC}_{50}$ value for each film.

\section{Conclusions}

Overall, these polymeric films have potential to be used in food packaging applications. Films with the pine stump extract and glycerol in their composition showed the highest thickness values. Glycerol was also responsible for the best elasticity of CBC films, while the addition of cellulose and silicone increased the water contact angle values. Water vapour transmission rate properties and water vapour sorption of pure CBC films were the most appropriate among all tested films, but close values were achieved for films with additives. The addition of the antioxidant pine stump extract may avoid the use of preservatives, increase food shelf life, and decrease photo-oxidation due to the opacity conferred by its brown colour. However, this extract revealed cytotoxicity for the tested cell line and should not be used in edible coatings for food packaging applications. Additional studies with cells, and gas permeability studies, may be further conducted, allowing to define the most appropriate foods to be packed with these films because the needs are different. An option may be some types of cheese, which do not require a clear packaging and have short shelf life.

\section{Author statement}

M. C. Gaspar: Conceptualization; Investigation; Visualization; Formal analysis Writing - original draft and final version.

M. E. M. Braga: Conceptualization; Supervision; Investigation; Visualization; Validation; Formal analysis; Writing - review \& editing.

J. Leocádio: Investigation; Formal analysis; Writing - review \& editing.

C. V. T. Mendes: Investigation; Formal analysis; Writing - review \& editing.

M. G. V. S. Carvalho: Formal analysis; Writing - review \& editing.

A. Matias: Formal analysis; Writing - review \& editing.

N. Hernández: Investigation; Formal analysis; Writing - review \& editing. 
I
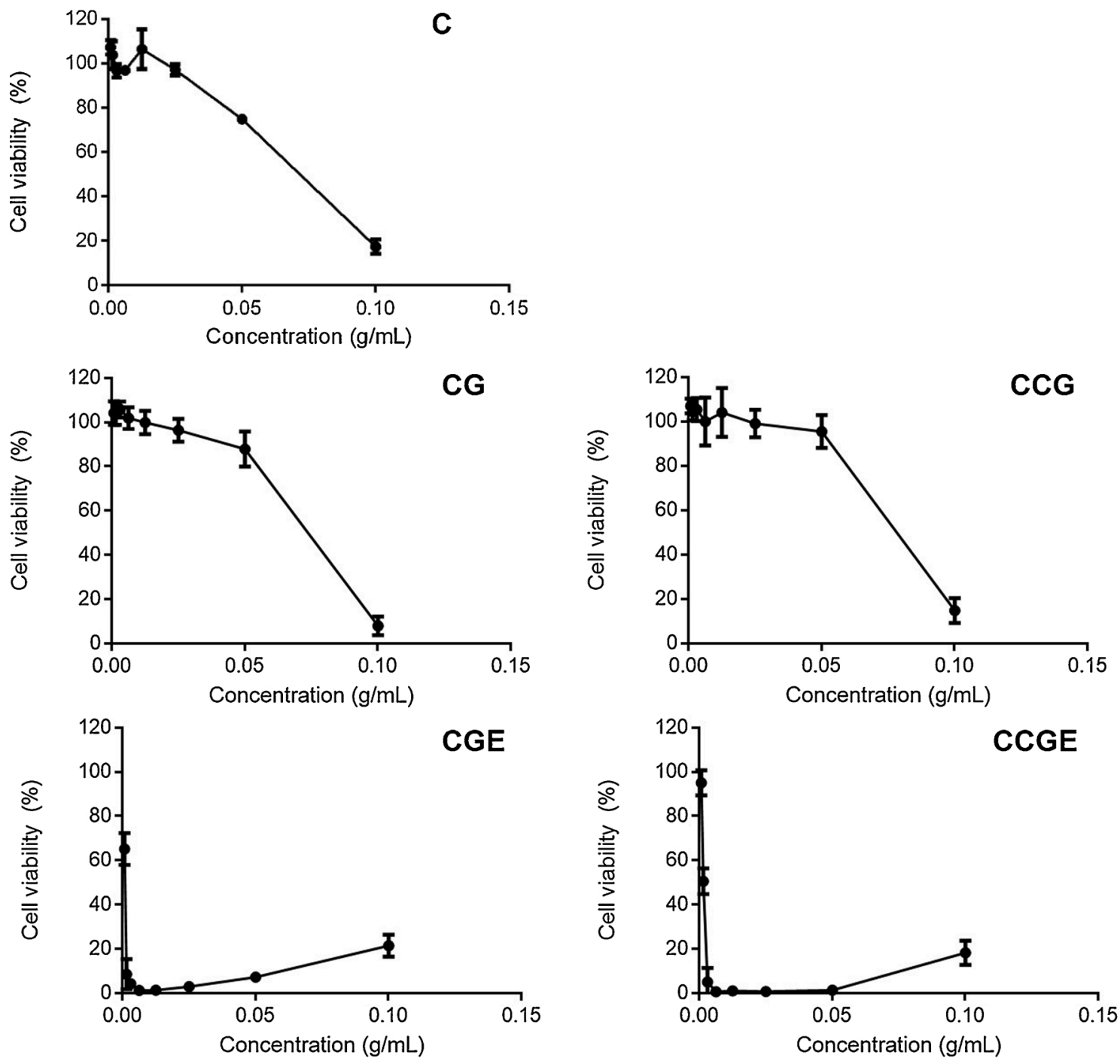

II

Glycerol

Pine stump extract
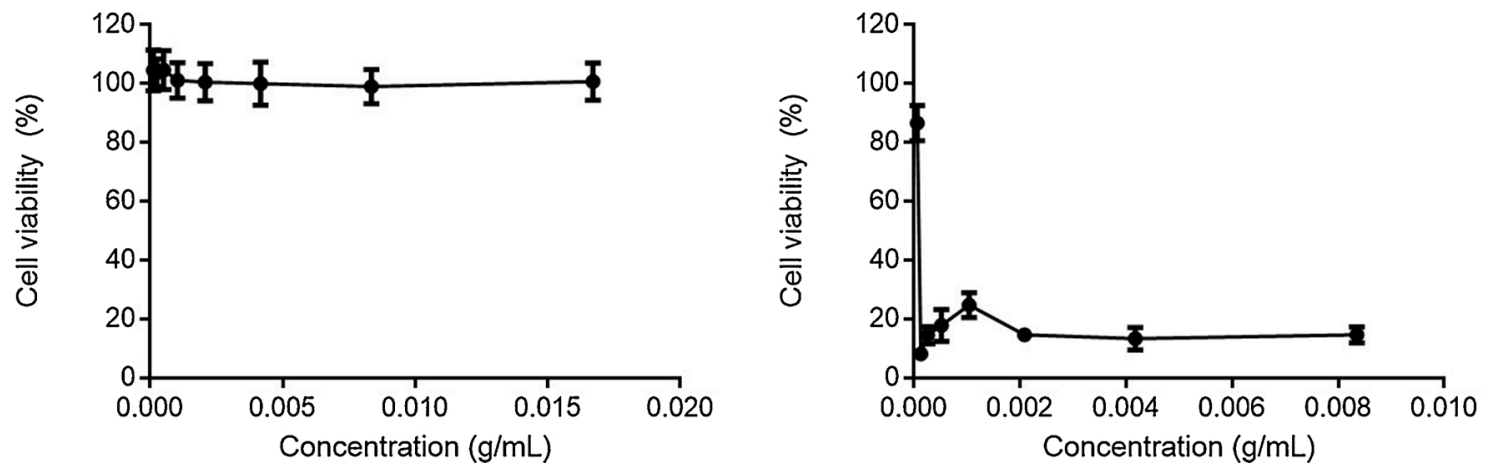

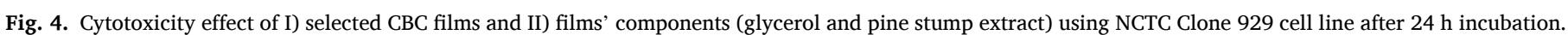

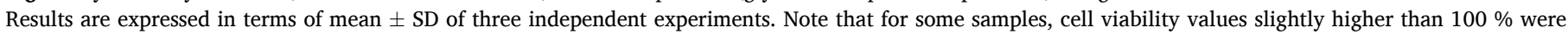
observed, which may be due to the presence of more cells in some wells. 
M. Cardeira: Investigation; Formal analysis; Writing - review \& editing.

\section{Declaration of Competing Interest}

The authors report no declarations of interest.

\section{Acknowledgements}

This work was financially supported by COMPETE 2020, Fundação para a Ciência e Tecnologia (FCT, Portugal), through the project "MultiBiorefinery - Multi-purpose strategies for broadband Agro-forest and fisheries by-products: a step forward for a truly integrated biorefinery POCI-01-0145-FEDER-016403", also through CIEPQPF (PEst-C/EQB/ UI0102/2019 and UIDB/00102/2020), and IBET (UIDB/04462/2020 and UIDP/04462/2020). M. C. Gaspar and C. V. T. Mendes acknowledge FCT for the financial support, CEECIND/00527/2017 and SFRH/BD/ $139908 / 2018$, respectively. The authors also thank to Santander Universidades and University of Coimbra for the award "Projetos Semente Santander UC". This paper is dedicated to the memory of A. T. Portugal, the University of Coimbra leader of Multibiorefinery project, for his partnership and commitment.

\section{Appendix A. Supplementary data}

Supplementary material related to this article can be found, in the online version, at doi:https://doi.org/10.1016/j.fpsl.2021.100661.

\section{References}

Atarés, L., \& Chiralt, A. (2016). Essential oils as additives in biodegradable films and coatings for active food packaging. Trends in Food Science \& Technology, 48, 51-62. https://doi.org/10.1016/j.tifs.2015.12.001

Bombaldi de Souza, R., Bombaldi de Souza, F. C., Angela, M., Bernard, D., \& Mantovani, D. (2016). Effect of addition of Pluronic F68 and Silpuran 2130 A/B to chitosan-xanthan matrices. Frontiers in Bioengineering and Biotechnology, 4. https:// doi.org/10.3389/conf.FBIOE.2016.01.02900

Cruz, R. M. S., Alves, V., Khmelinskii, I., \& Vieira, M. C. (2018). In A. M. Grumezescu, \& A. M. Holban (Eds.), Chapter 2 - new food packaging systems. Food packaging and preservation (pp. 63-85). Academic Press. https://doi.org/10.1016/B978-0-12811516-9.00002-6.

de Moraes Crizel, T., de Oliveira Rios, A., Alves, V. D., Bandarra, N., Moldão-Martins, M. \& Hickmann Flôres, S. (2018). Active food packaging prepared with chitosan and olive pomace. Food Hydrocolloids, 74, 139-150. https://doi.org/10.1016/j. foodhyd.2017.08.007

Dias, A. M. A., Braga, M. E. M., Seabra, I. J., Ferreira, P., Gil, M. H., \& de Sousa, H. C. (2011). Development of natural-based wound dressings impregnated with bioactive compounds and using supercritical carbon dioxide. International Journal of Pharmaceutics, 408(1), 9-19. https://doi.org/10.1016/j.ijpharm.2011.01.063

dos Santos, K. S. C. R., Silva, H. S. R. C., Ferreira, E. I., \& Bruns, R. E. (2005). $3^{2}$ Factorial design and response surface analysis optimization of N-carboxybutylchitosan synthesis. Carbohydrate Polymers, 59(1), 37-42. https://doi.org/10.1016/j. carbpol.2004.08.020

Eurostat. (2020). In Eurostat (Ed.), Packaging waste statistics. http://ec.europa.eu/eurosta $\mathrm{t} /$ product? code $=$ env waspac\&language $=$ en\&mode $=$ view.

Falguera, V., Quintero, J. P., Jiménez, A., Muñoz, J. A., \& Ibarz, A. (2011). Edible films and coatings: Structures, active functions and trends in their use. Trends in Food Science \& Technology, 22(6), 292-303. https://doi.org/10.1016/j.tifs.2011.02.004

Farahnaky, A., Saberi, B., \& Majzoobi, M. (2013). Effect of glycerol on physical and mechanical properties of wheat starch edible films. Journal of Texture Studies, 44(3), 176-186. https://doi.org/10.1111/jtxs.12007

Gaspar, M. C., Mendes, C. V. T., Pinela, S. R., Moreira, R., Carvalho, M. G. V. S., Quina, M. J., ... Portugal, A. T. (2019). Assessment of agroforestry residues: Their potential within the biorefinery context. ACS Sustainable Chemistry \& Engineering, 7 (20), 17154-17165. https://doi.org/10.1021/acssuschemeng.9b03532

Geueke, B. (2015). FPF dossier: Silicones. Zenodo.

Gontard, N., Guilbert, S., \& Cuq, J.-L. (1993). Water and glycerol as plasticizers affect mechanical and water vapor barrier properties of an edible wheat gluten film. Journal of Food Science, 58(1), 206-211. https://doi.org/10.1111/j.1365-2621.1993. tb03246.x

Guimarães, J., Cursino, A., Saul, C., Sierrakowski, M., Pereira Ramos, L., \& Satyanarayana, K. G. (2016). Evaluation of Castor oil cake starch and recovered glycerol and development of "Green" composites based on those with plant fibers. Materials, 9, 76. https://doi.org/10.3390/ma9020076

Haghighi, H., Licciardello, F., Fava, P., Siesler, H. W., \& Pulvirenti, A. (2020). Recent advances on chitosan-based films for sustainable food packaging applications. Food
Packaging and Shelf Life, 26, Article 100551. https://doi.org/10.1016/j. fpsl.2020.100551

Hassanzadeh, P., Tajik, H., Rohani, S. M. R., Moradi, M., Hashemi, M., \& Aliakbarlu, J. (2017). Effect of functional chitosan coating and gamma irradiation on the shelf-life of chicken meat during refrigerated storage. Radiation Physics and Chemistry, 141, 103-109. https://doi.org/10.1016/j.radphyschem.2017.06.014

ISO. (1993). Part 1: General principles. Plastics - Determination of tensile properties Switzerland. International Organization for Standardization. ISO, 527-1:1993(E).

ISO. (1996). Part 2: Test conditions for moulding and extrusion plastics. Plastics Determination of tensile properties. 527-2 (p. 6). Berlin: DIN.

ISO. (2004). Sample preparation and reference materials. Biological evaluation of medical devices, BSI British Standards. BS EN ISO, 10993-12:2004.

ISO. (2009). Tests for in vitro cytotoxicity. Biological evaluation of medical devices. International Organization for Standardization Switzerland, ISO, 10993-10995:2009 (E).

Leimann, F. V., Gonçalves, O. H., Sakanaka, L. S., Azevedo, A. S. B., Lima, M. V., Barreiro, F., \& Shirai, M. A. (2018). In A. M. Grumezescu, \& A. M. Holban (Eds.), Chapter 3 - active food packaging from botanical, animal, bacterial, and synthetic sources. Food packaging and preservation (pp. 87-135). Academic Press. https://doi.org/ 10.1016/B978-0-12-811516-9.00003-8.

Lekjing, S. (2016). A chitosan-based coating with or without clove oil extends the shelf life of cooked pork sausages in refrigerated storage. Meat Science, 111, 192-197. https://doi.org/10.1016/j.meatsci.2015.10.003

Liu, J., Liu, S., Wu, Q., Gu, Y., Kan, J., \& Jin, C. (2017). Effect of protocatechuic acid incorporation on the physical, mechanical, structural and antioxidant properties of chitosan film. Food Hydrocolloids, 73, 90-100. https://doi.org/10.1016/j. foodhyd.2017.06.035

Meiron, T. S., \& Saguy, I. S. (2007). Wetting properties of food packaging. Food Research International, 40(5), 653-659. https://doi.org/10.1016/j.foodres.2006.11.010

Mendes, C. V. T., Vergara, P., Carbajo, J. M., Villar, J. C., Rocha, J. M.d. S., \& Carvalho, M. G. V. S. (2020). Bioconversion of pine stumps to ethanol: Pretreatment and simultaneous saccharification and fermentation. Holzforschung, 74(2), 212-216. https://doi.org/10.1515/hf-2018-0126

Meritaine da, R., de Souza, M. M., \& Prentice, C. (2018). In A. M. Grumezescu, \& A. M. Holban (Eds.), Chapter 9 - biodegradable films: An alternative food packaging. Food packaging and preservation (pp. 307-342). Academic Press. https://doi.org/ 10.1016/B978-0-12-811516-9.00009-9.

Moreira Gonçalves, S., Gomes Motta, J. F., Ribeiro-Santos, R., Hidalgo Chávez, D. W., \& Ramos de Melo, N. (2020). Functional and antimicrobial properties of cellulose acetate films incorporated with sweet fennel essential oil and plasticizers. Current Research in Nutrition and Food Science Journal, 3, 1-8. https://doi.org/10.1016/j. crfs.2020.01.001

Mujtaba, M., Morsi, R. E., Kerch, G., Elsabee, M. Z., Kaya, M., Labidi, J., \& Khawar, K. M. (2019). Current advancements in chitosan-based film production for food technology; A review. International Journal of Biological Macromolecules, 121, 889-904. https://doi.org/10.1016/j.ijbiomac.2018.10.109

Mujtaba, M., Salaberria, A. M., Andres, M. A., Kaya, M., Gunyakti, A., \& Labidi, J. (2017). Utilization of flax (Linum usitatissimum) cellulose nanocrystals as reinforcing material for chitosan films. International Journal of Biological Macromolecules, 104, 944-952. https://doi.org/10.1016/j.ijbiomac.2017.06.127

Müller, C. M. O., Laurindo, J. B., \& Yamashita, F. (2009). Effect of cellulose fibers addition on the mechanical properties and water vapor barrier of starch-based films. Food Hydrocolloids, 23(5), 1328-1333. https://doi.org/10.1016/j. foodhyd.2008.09.002

Muxika, A., Zugasti, I., Guerrero, P., \& De la Caba, K. (2018). Applications of chitosan in food packaging. https://doi.org/10.1016/B978-0-08-100596-5.22400-1

Muzzarelli, R., Weckx, M., Filippini, O., \& Lough, C. (1989). Characteristic properties of N-Carboxybutyl chitosan. Carbohydrate Polymers, 11(4), 307-320. https://doi.org/ 10.1016/0144-8617(89)90005-2

Ortega-Fernandez, C., Gonzalez-Adrados, J. R., García-Vallejo, M. C., Calvo-Haro, R., \& Caceres-Esteban, M. J. (2006). Characterization of surface treatments of cork stoppers by FTIR-ATR. Journal of Agricultural and Food Chemistry, 54(14), 4932-4936. https://doi.org/10.1021/jf0529823

Pagliaro, M., \& Rossi, M. (2008). In M. Rossi (Ed.), Glycerol: Properties and production. The future of glycerol: New uses of a versatile raw material (p. 104). Royal Society of Chemistry, Springer.

Pires, A. L. R., de Azevedo Motta, L., Dias, A. M. A., de Sousa, H. C., Moraes, Â. M., \& Braga, M. E. M. (2018). Towards wound dressings with improved properties: Effects of poly(dimethylsiloxane) on chitosan-alginate films loaded with thymol and betacarotene. Materials Science and Engineering: C, 93, 595-605. https://doi.org/ 10.1016/j.msec.2018.08.005

Pradhan, G. C., Dash, S., \& Swain, S. K. (2015). Barrier properties of nano silicon carbide designed chitosan nanocomposites. Carbohydrate Polymers, 134, 60-65. https://doi. org/10.1016/j.carbpol.2015.06.081

Ren, L., Yan, X., Zhou, J., Tong, J., \& Su, X. (2017). Influence of chitosan concentration on mechanical and barrier properties of corn starch/chitosan films. International Journal of Biological Macromolecules, 105, 1636-1643. https://doi.org/10.1016/j. ijbiomac.2017.02.008

Rinaudo, M., Desbrières, J., Le Dung, P., Thuy Binh, P., \& Dong, N. T. (2001). NMR investigation of chitosan derivatives formed by the reaction of chitosan with levulinic acid. Carbohydrate Polymers, 46(4), 339-348. https://doi.org/10.1016/ S0144-8617(00)00333-7

Rui, L., Xie, M., Hu, B., Zhou, L., Yin, D., \& Zeng, X. (2017). A comparative study on chitosan/gelatin composite films with conjugated or incorporated gallic acid. Carbohydrate Polymers, 173, 473-481. https://doi.org/10.1016/j. carbpol.2017.05.072 
Serrano-León, J. S., Bergamaschi, K. B., Yoshida, C. M. P., Saldaña, E., Selani, M. M., Rios-Mera, J. D., Alencar, S. M., \& Contreras-Castillo, C. J. (2018). Chitosan active films containing agro-industrial residue extracts for shelf life extension of chicken restructured product. Food Research International, 108, 93-100. https://doi.org/ 10.1016/j.foodres.2018.03.031

Shen, Z., \& Kamdem, D. P. (2015). Development and characterization of biodegradable chitosan films containing two essential oils. International Journal of Biological Macromolecules, 74, 289-296. https://doi.org/10.1016/j.ijbiomac.2014.11.046

Siracusa, V. (2016). In J. Barros-Velázquez (Ed.), Chapter 7 - packaging material in the food industry. Antimicrobial food packaging (pp. 95-106). San Diego: Academic Press. https://doi.org/10.1016/B978-0-12-800723-5.00007-3.

Siracusa, V., Rocculi, P., Romani, S., \& Rosa, M. D. (2008). Biodegradable polymers for food packaging: A review. Trends in Food Science \& Technology, 19(12), 634-643. https://doi.org/10.1016/j.tifs.2008.07.003

Souza, H. K. S., Campiña, J. M., Sousa, A. M. M., Silva, F., \& Gonçalves, M. P. (2013) Ultrasound-assisted preparation of size-controlled chitosan nanoparticles: Characterization and fabrication of transparent biofilms. Food Hydrocolloids, 31(2), 227-236. https://doi.org/10.1016/j.foodhyd.2012.10.005

Souza, V. G. L., Fernando, A. L., Pires, J. R. A., Rodrigues, P. F., Lopes, A. A. S., \& Fernandes, F. M. B. (2017). Physical properties of chitosan films incorporated with natural antioxidants. Industrial Crops and Products, 107, 565-572. https://doi.org/ 10.1016/j.indcrop. 2017.04.056

Suesca, E., Dias, A. M. A., Braga, M. E. M., de Sousa, H. C., \& Fontanilla, M. R. (2017). Multifactor analysis on the effect of collagen concentration, cross-linking and fiber/ pore orientation on chemical, microstructural, mechanical and biological properties of collagen type I scaffolds. Materials Science and Engineering: C, 77, 333-341. https://doi.org/10.1016/j.msec.2017.03.243

Tian, H., Wang, Y., Zhang, L., Quan, C., \& Zhang, X.-Z. (2010). Improved flexibility and water resistance of soy protein thermoplastics containing waterborne polyurethane. Industrial Crops and Products, 32, 13-20. https://doi.org/10.1016/j. indcrop.2010.02.009

Vlacha, M., Giannakas, A., Katapodis, P., Stamatis, H., Ladavos, A., \& Barkoula, N.-M. (2016). On the efficiency of oleic acid as plasticizer of chitosan/clay nanocomposites and its role on thermo-mechanical, barrier and antimicrobial properties Comparison with glycerol. Food Hydrocolloids, 57, 10-19. https://doi.org/10.1016/j. foodhyd.2016.01.003

Ziani, K., Oses, J., Coma, V., \& Maté, J. I. (2008). Effect of the presence of glycerol and Tween 20 on the chemical and physical properties of films based on chitosan with different degree of deacetylation. LWT - Food Science and Technology, 41(10), 2159-2165. https://doi.org/10.1016/j.lwt.2007.11.023 